\title{
Investigation of the Thermal Improvement and the Kinetic Analysis of the Enriched Coal
}

\author{
Selma Duzyol ${ }^{1}{ }^{1}$ and Cem Sensogut ${ }^{2}$ \\ ${ }^{1}$ Department of Mining Engineering, Selcuk University, 42075 Konya, Turkey \\ ${ }^{2}$ Department of Mining Engineering, Dumlupinar University, 43100 Kutahya, Turkey \\ Correspondence should be addressed to Selma Duzyol; selmad@selcuk.edu.tr
}

Received 12 January 2018; Revised 17 April 2018; Accepted 2 May 2018; Published 19 June 2018

Academic Editor: Kun Luo

Copyright ( 2018 Selma Duzyol and Cem Sensogut. This is an open access article distributed under the Creative Commons Attribution License, which permits unrestricted use, distribution, and reproduction in any medium, provided the original work is properly cited.

\begin{abstract}
The present research work is comprised of three main parts. The first part is about the enrichment of lignite coal by the utilization of dense medium separation called float and sink method. The second part deals with the investigation of the thermal behaviour for the coals enriched while the last part is concerned with the kinetic analysis of the coal combustion. The float and sink method is the mostly used technique for low-rank coal beneficiation in coal preparation plants of Turkey. In order to realize this process, the coal samples were, at first, fractioned to five different sizes which were $-32+25 \mathrm{~mm},-25+16 \mathrm{~mm},-16+8 \mathrm{~mm},-8+4.75 \mathrm{~mm}$, and $-4.75+2 \mathrm{~mm}$. Each fraction was, then, processed in the dense mediums with the specific gravities of 1.20, 1.30, 1.40, 1.50, and 1.60 $\mathrm{g} / \mathrm{cm}^{3}$, respectively. The thermal behaviour of the floated materials from the float and sink process was investigated in detail with the thermogravimetric analysis (TG) and the differential thermogravimetric analysis (DTG). The ignition and peak temperatures for the samples were also ascertained and correlated with the float and sink test results. In the final part of the study, the kinetic analysis of the coal samples was carried out by the Coats-Redfern method and the activation energies of the enriched coals were determined. The activation energies of the raw and the enriched coals were assessed and compared. The calculated activation energy values for the combustion reactions of the coal samples ranged were found to be between $15.17 \mathrm{~kJ} / \mathrm{mol}$ and $97.45 \mathrm{~kJ} / \mathrm{mol}$. The strong correlation was obtained between the float and sink test results especially with the ash content of the coal samples and the combustible characteristic of the floated materials such as ignition temperatures, peak temperatures, and activation energies. The combustion characteristics of the coal samples were resultantly ascertained to be very dependent on the coal structure.
\end{abstract}

\section{Introduction}

Coal is a crucial source of the energy supply in many countries and for steel, cement, and concrete industries. The coal reserves including newly explored basins have reached to the sum of 15.4 billion tons at the end of the year 2014 in Turkey. The 14.1 billion tons of the coal reserves (about $92 \%$ of total) are lignite coals [1]. The lignite coals of Turkey were evaluated mostly in power generation because of their subdued calorific value and high ash content. Coal has a heterogeneous structure and complex mixture of organic and inorganic species in general. These specifications of coal limit its utilization from time to time and cause some serious problems in practice. It is important to increase the quality of coal by reducing its ash content, hence increasing its calorific value. Therefore, cleaning of the coal is a process via comprising the removal of incombustible materials from coal. Many enrichment practices can be applied for the beneficiation of the coal such as jigging, dense media separation, froth flotation, oil agglomeration, shaking tables, washing cyclones, etc. Amongst these methods, the dense medium application mostly is used in the coal beneficiation plants in Turkey due to the larger upper limit of separation and the acceptable efficiency. Advanced cleaning possibilities of lowrank coals have been studied by many researchers $[2,3]$. The further investigation of sink and float process was employed by many other researchers. Aktas et al. [4] used centrifugal float and sink separation technic in heavy medium and investigated the contribution of surface active agents for several Turkish coals. They had a conclusion of that the separation 
TABLE 1: The specifications of coal sample $*[31]$.

\begin{tabular}{|c|c|c|c|c|c|c|c|c|}
\hline $\begin{array}{l}\text { density } \\
\text { (ton } / \mathrm{m}^{3} \text { ) }\end{array}$ & $\begin{array}{l}\text { Ash } \\
(\%) \\
\end{array}$ & $\begin{array}{c}\text { Moisture } \\
(\%)\end{array}$ & $\begin{array}{l}\text { Lower calorific } \\
\text { value (kcal/kg) }\end{array}$ & $\begin{array}{c}\mathrm{C} \\
(\%) \\
\end{array}$ & $\begin{array}{c}\mathrm{H} \\
(\%) \\
\end{array}$ & $\begin{array}{c}\mathrm{N} \\
(\%)\end{array}$ & $\begin{array}{c}\mathrm{O} \\
(\%) \\
\end{array}$ & $\begin{array}{c}\mathrm{S} \\
(\%) \\
\end{array}$ \\
\hline $1.5 *$ & 35.84 & 12.85 & $2482 *$ & 30.2 & 3.01 & 1.0 & 15.3 & 1.8 \\
\hline
\end{tabular}

efficiency much depended on the rank of coal. Tian et al. [5] applied low temperature oxygen-plasma ashing method before float and sink experiments for the determination of mineralogical characteristic and trace element affinities of coals collected from different regions of China. The light and heavy minerals isolated from the organic component of coal were separated according to their different densities by this method. Guanghui et al. [6] also developed a method which rapidly predicted the density compounds of run of mine coal. Their model processes the data obtained from floats and sinks along with standardized monthly production data as rapid as possible and more reliable prediction of gravity separation. Some other researchers additionally improved mathematical modelling for cleaning of coal [7-9]. Ozer [10] introduced a new cheap experimental setup for density fractionating of fine coal samples by putting the principles of separating funnel and funnel-flask methods together.

Dense medium separation not only utilizes sulphur and ash rejection but also increases the calorific value of coal. Therefore, the characterization of coal for combustion would be improved and thermal behaviour of coal would be changed.

The thermal behaviour of coal is determined mostly by using TG. Although, many works on biomass combustion with TG [11-15] and coal combustion [16-23] are available in the literature, investigations on 'enriched coal' are rather less [24-26]. The enrichment of coal provides an opportunity for the separation of coals and their maceral composition due to the difference of densities [27].

Indian researchers [12] investigated the possible usage of biomass products with pulverized coal due to the foresight of the increase in energy demand. They determined the TGA parameters such as activation energy and ignition index to assess the combustion features of coal blends with different biomass chars which would be helpful for identifying suitable biomass-type and blend proportion for a given coal in order to reveal some exclusive advantages in terms of particular combustion exercise. Podder and his coworkers [16] also investigated the thermal behaviours of Bangladeshi coals by TGA analysis. They observed the primary and secondary devolatization sections when the coal was heated up to $600^{\circ} \mathrm{C}$. In addition, the combustion specifications of biomass fuels and lignite coals were studied by Turkish researchers [17]. They concluded that low-rank coals with biomass could be efficiently burnt. In a different research, the low-rank Indian coals were agglomerated by using binders for the preparation of cooking [25] and the combustion characteristics were determined by TG and DTA analyses.

DTG was the first thermoanalytical implementation utilized in the investigation of the thermal behaviour of coal. DTG also provides to investigate of decomposition reactions in coal. A derivative weight loss curve can be put into practice to point out the ignition and peak temperatures at which the weight loss is the most apparent [28, 29]. The reaction kinetics of coals is also determined from thermogravimetric analysis [30].

The primary purpose of the present work is to evaluate the washability characteristics of lignite coal via float and sink method and the influence of the enrichment on combustible behaviour of the coal. Therefore, the thermal and kinetic analyses were performed on the beneficiated coal samples. The strong relation was seen between the physical features of the products obtained from float and sink experiments and combustion results. The TG and DTG characteristics, ignition temperatures, peak temperatures, and activation energies were also analysed and the obtained results were explicated comparatively.

\section{Experimental}

2.1. Coal Sample Specifications. The run of mine (RoM) lignite coal from Orhaneli (Bursa) district of Turkey was used in the float and sink tests. The specifications of the coal sample were given in Table 1 [31]. It was determined that the raw coal sample has a high ash content value of $35.84 \%$. The coal sample was screened as soon as received and sieved to five fractions as $-32+25 \mathrm{~mm},-25+16 \mathrm{~mm},-16+8 \mathrm{~mm},-8+4.75 \mathrm{~mm}$, and $-4.75+2 \mathrm{~mm}$. The particle size distribution of raw coal was also determined and illustrated in Figure 1. Each fraction was washed and percolated before the float and sink experiments.

\subsection{Experimental Procedures}

2.2.1. Float and Sink Experiments. All fractions were processed separately in dense media with the densities of 1.20, $1.30,1.40,1.50$, and $1.60 \mathrm{~g} / \mathrm{cm}^{3}$. The dense mediums were prepared with $-45 \mu \mathrm{m}$ size of magnetite and tap water. Each fractioned coal sample was dipped into the dense medium starting with higher density to lower density step by step. The constituents with a density lower than the dipped medium's density floated and the floated particles were transferred in the lighter medium. The float products were washed and percolated before placed in the lower density liquid. This treatment was repeated until the lightest medium was reached. The sunken parts were separated from the liquid and washed away to remove the magnetite content from the coal. Thereafter, the products were dried, weighted, and then prepared for thermal analysis. In addition, the dense medium was stirred rather slowly to avoid magnetite sinking.

2.2.2. Thermogravimetric Analyses. Thermogravimetric analysis is often used in ascertaining the thermal attitude of solid fuels as shown in many previous works. Therefore, Polymer 


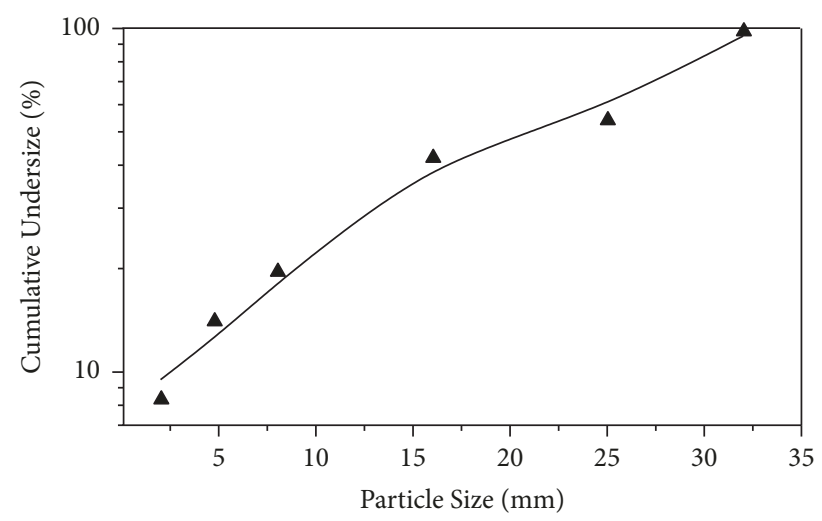

FIGURE 1: Particle size distribution of coal sample.

Laboratories PL-TGA 1500 thermal analyser was used for the thermogravimetric analysis of floated coal samples obtained from float and sink tests. Detailed schematic representation of the experimental procedure can be found in the literature [32].

After float and sink experiments, each obtained sample was reduced into the same particle size which was less than $100 \mu \mathrm{m}$ by using laboratory type of ceramic ball mill. About ten milligrams of samples was heated up to $900^{\circ} \mathrm{C}$ at a constant rate of $10^{\circ} \mathrm{C} / \mathrm{min}$ in a $5 \mathrm{~mL} / \mathrm{min}$ flow of dry air. Then, the variation of sample mass in accordance with the heating rate was analysed in real time. Prior to thermogravimetric analysis of samples, the calibration of device has been carried out both for the mass and for the temperature. TG and DTG curves were derived from the analysis and the ignition and the peak temperatures of the samples were found using DTG curves according to the following:

$$
\frac{T_{\text {final }}-T_{\text {inital }}}{t_{\text {final }}-t_{\text {inital }}}=\frac{d W}{d t}
$$

where $T$ is temperature $\left({ }^{\circ} \mathrm{C}\right), t$ is time (min), and $W(\mathrm{mg})$ is weight of sample. Analysis of each sample was repeated twice at least and repeatability was checked. The repeatability of the tests was found to be more than 99\%. In addition, some of the experiments were performed twice at least to test the reproducibility of the results with standards errors of \pm $1^{\circ} \mathrm{C}$, to be reached. The peak and the ignition temperatures of the lignite coal sample can be obtained from burning profile and DTG curve. While the first peak indicates the ignition temperature, the second peak represents the peak temperature. Typical TG and DTG curves of lignite coal (RoM) were given in Figure 2. The weight loss of coal was raised with an increase in temperature. The ignition and peak temperatures were found to be $204^{\circ} \mathrm{C}$ and $398^{\circ} \mathrm{C}$, respectively, from DTG curve. It is stated from the literature that the more reactive the coal is, the lower the maximum peak temperature is $[29,33-35]$.

2.2.3. Kinetic Analyses. The Coats and Redfern [36] approach based on the Arrhenius equation was used in the present work for the calculation of the kinetic parameters. This integral

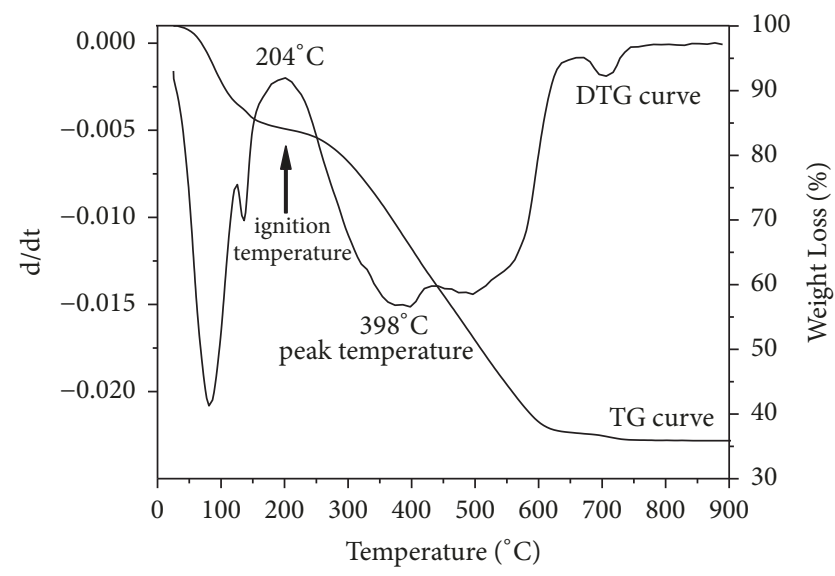

FIGURE 2: TG and DTG curves with ignition and peak temperatures of the coal sample.

method can be implemented to TG/DTG data, assuming the reactions order $\mathrm{n}$ as 1 . The correct order is foreseen to lead to the best linear plot, from which the activation energy is appointed.

The final equation derived by this method is as follows:

$$
\ln \left[-\frac{\ln (1-\alpha)}{T^{2}}\right]=\ln \left[\frac{A_{r} \mathrm{R}}{\beta E}\left(1-\frac{2 R T}{E}\right)\right]-\frac{E}{R T}
$$

In (2), $T$ is temperature; $A_{r}$ is Arrhenius constant; $\beta$ is constant heating rate; $E$ is activation energy; $\alpha$ is weight loss degrees which can be calculated by

$$
\alpha=\frac{W_{0}-W_{t}}{W_{0}-W_{f}}
$$

where $W_{0}$ is the initial weight of sample; $W_{f}$ is the final weight of sample after burnt down.

According to the Coats and Redfern method, the expression $\ln \left[\left(A_{r} R / \beta E\right)(1-2 R T / E)\right]$ in (2) is specifically constant under most circumstances. Plots of $\ln \left[-\ln (1-\alpha) / T^{2}\right]$ against $1 / T$, a straight line should be obtained. The straight line with the maximum correlation coefficient will be taken as the function of the model that best expresses the kinetics of mass loss. Therefore, the activation energy, $E$, can be obtained from the slope of the line, $-E / R$.

\section{Results and Discussion}

3.1. The Results of the Float and Sink Experiments. The results of the float and sink experiments were given in Table 2 for all fractions.

In the Table 2, the highest yield of sinking part was achieved as $25.44 \%$ from the $-32+25 \mathrm{~mm}$ fraction at specific gravity of $1.60 \mathrm{~g} / \mathrm{cm}^{3}$ medium. The ash content of floating part in the $-25+16 \mathrm{~mm}$ fraction at $1.20 \mathrm{~g} / \mathrm{cm}^{3}$ specific density which had the minimum ash content as $4.51 \%$ was the $13.50 \%$ of the total sum of coal. This value was the lowest ash content obtained from the all float and sink tests. The ash content of floating parts at 1.20 and $1.30 \mathrm{~g} / \mathrm{cm}^{3}$ of specific densities was 
TABLE 2: The results of float and sink experiments.

\begin{tabular}{|c|c|c|c|c|c|c|c|c|c|c|c|}
\hline \multicolumn{2}{|c|}{ Specific gravity range } & \multicolumn{2}{|c|}{$\begin{array}{c}-32+25 \mathrm{~mm} \\
\text { Float }\end{array}$} & \multicolumn{2}{|c|}{$\begin{array}{c}-25+16 \mathrm{~mm} \\
\text { Float }\end{array}$} & \multicolumn{2}{|c|}{$\begin{array}{c}-16+8 \mathrm{~mm} \\
\text { Float }\end{array}$} & \multicolumn{2}{|c|}{$\begin{array}{c}-8+4.75 \mathrm{~mm} \\
\text { Float }\end{array}$} & \multicolumn{2}{|c|}{$\begin{array}{c}-4.75+2 \mathrm{~mm} \\
\text { Float }\end{array}$} \\
\hline & & $\begin{array}{c}\text { Weight } \\
(\%)\end{array}$ & $\begin{array}{l}\text { Ash } \\
(\%)\end{array}$ & $\begin{array}{c}\text { Weight } \\
(\%)\end{array}$ & $\begin{array}{l}\text { Ash } \\
(\%)\end{array}$ & $\begin{array}{c}\text { Weight } \\
(\%)\end{array}$ & $\begin{array}{l}\text { Ash } \\
(\%)\end{array}$ & $\begin{array}{c}\text { Weight } \\
(\%)\end{array}$ & $\begin{array}{l}\text { Ash } \\
(\%)\end{array}$ & $\begin{array}{c}\text { Weight } \\
(\%)\end{array}$ & $\begin{array}{l}\text { Ash } \\
(\%)\end{array}$ \\
\hline & -1.20 & 16.34 & 6.32 & 13.50 & 4.51 & 27.72 & 7.69 & 33.39 & 7.74 & 34.92 & 6.27 \\
\hline+1.20 & -1.30 & 2.59 & 7.34 & 5.77 & 6.13 & 10.94 & 8.56 & 35.81 & 8.28 & 24.00 & 8.42 \\
\hline+1.30 & -1.40 & 21.72 & 7.45 & 55.94 & 9.55 & 25.77 & 10.48 & 21.61 & 14.44 & 26.00 & 13.41 \\
\hline+1.40 & -1.50 & 24.02 & 9.49 & 11.68 & 13.01 & 24.78 & 12.99 & 3.18 & 38.00 & 3.97 & 24.39 \\
\hline+1.50 & -1.60 & 9.89 & 27.24 & 2.70 & 21.40 & 0.69 & 28.29 & 0.63 & 36.13 & 5.79 & 23.74 \\
\hline+1.60 & & 25.44 & 83.03 & 10.41 & 78.43 & 10.10 & 76.31 & 5.38 & 79.53 & 5.32 & 76.35 \\
\hline
\end{tabular}

very close for all fractions. In addition, the $-4.75+2 \mathrm{~mm}$ size was the finest fraction in the experiments and the quantity of the floating part was quite a few at higher density mediums. The yield of floated material was $84.92 \%$ of total amount of sample under the specific gravity of $1.40 \mathrm{~g} / \mathrm{cm}^{3}$ mediums at this fraction. Similar trend was followed for $-8+4.75 \mathrm{~mm}$ size fraction. It was observed that when the density of the medium reached the coal density, the amount of the floated material was decreased significantly. The separation sensitivity was also lowered at 1.40 and $1.50 \mathrm{~g} / \mathrm{cm}^{3}$ of specific densities of medium due to the approaching densities of both the coal samples and the medium. In addition, this decrease in the separation efficiency occurring because of the size may be due to the slower rate of settling of particles [37].

Whereas the ash content of sink materials of $-32+25$ $\mathrm{mm}$ fraction was $83.03 \%$, it was decreased to $76.35 \%$ for $4.75+2 \mathrm{~mm}$ fraction at the specific density of $1.60 \mathrm{~g} / \mathrm{cm}^{3}$. This discrepancy was arising from the size differences of fractions. The separation efficiency of the inorganic compounds from the coal was enhanced with a decrease in the size of fractions according to the liberalisation. However, the effectiveness of specific gravity of medium on the particles would also decrease with the decrement of the particle size. In addition, it was concluded that when the specific gravity of dense medium reached the coal density $\left(1.50 \mathrm{~g} / \mathrm{cm}^{3}\right)$, the amount of floated material was decreased significantly.

The ash content of floated materials from all fractions at different dense mediums was illustrated in Figure 3. The average ash content of all fractions at the specific gravity of $1.60 \mathrm{~g} / \mathrm{cm}^{3}$ was about $80 \%$.

3.2. Thermal Behaviour of the Enriched Coal. Coal is also identified as consisting primarily of hydroaromatic and aromatic clusters linked by aliphatic bridges $[38,39]$. When coal is heated, small amounts of pyrolysis water move away from the structures at around $300-350^{\circ} \mathrm{C}$ [40]. At $350^{\circ} \mathrm{C}$, primary carbonization starts initially with the release of carbon dioxide and hydrogen. Methane and other lower aliphatic are evolved together with hydrogen, carbon monoxide, and alkyl aromatics with warming up at last [41]. The physical, chemical, and thermal changes of heating coal are directly related to the coal components. Therefore, burning profiles of enriched coals were investigated using TG analysis depending on the available circumstances in the laboratory. The derivatives of

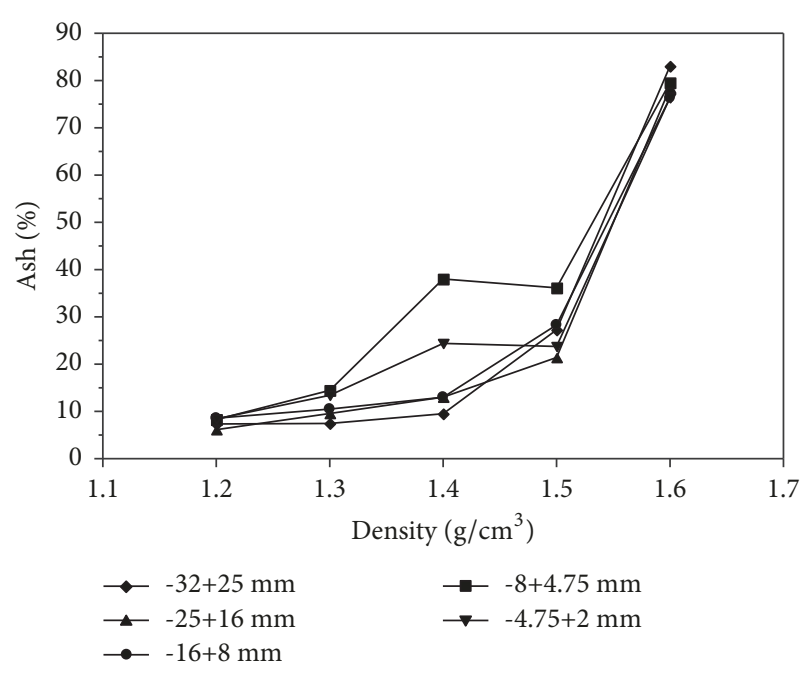

FIGURE 3: The ash contents of floated materials for all fractions at different specific gravities of medium.

TG curves were also estimated from the thermal profile of coal samples. The TG behaviour of floated materials from the float and sink experiments at different specific gravity of mediums for various size fractions was given in Figure 4. The sample code indicates the specific gravity of mediums. For example, the curve of 1.2 implies the floated materials obtained from the specific gravity of $1.2 \mathrm{~g} / \mathrm{cm}^{3}$ medium. TG curves show the weight loss of the coal depending on the time relevant to heating. When evaluating all samples on their own merits, it might be seen that the whole burning profiles behaved in similar trend. This is related to similar chemical structures. The weight losses of the samples from $1.6 \mathrm{~g} / \mathrm{cm}^{3}$ density for all fractions were lower than the others due to the higher quantity of inorganic materials. According to TG results, three regions were observed on thermographs. The first region was the weight loss due to the elimination of moisture, the second and the third were due to the devolatilization. The main weight loss occurring in second region was due to oxidation and removal of the volatile matters and combustion of carbonaceous parts of the coal samples. After the volatiles were removed from the samples, the third region was seen in connection with the oxidation of the char remaining [11]. In addition, the samples having 

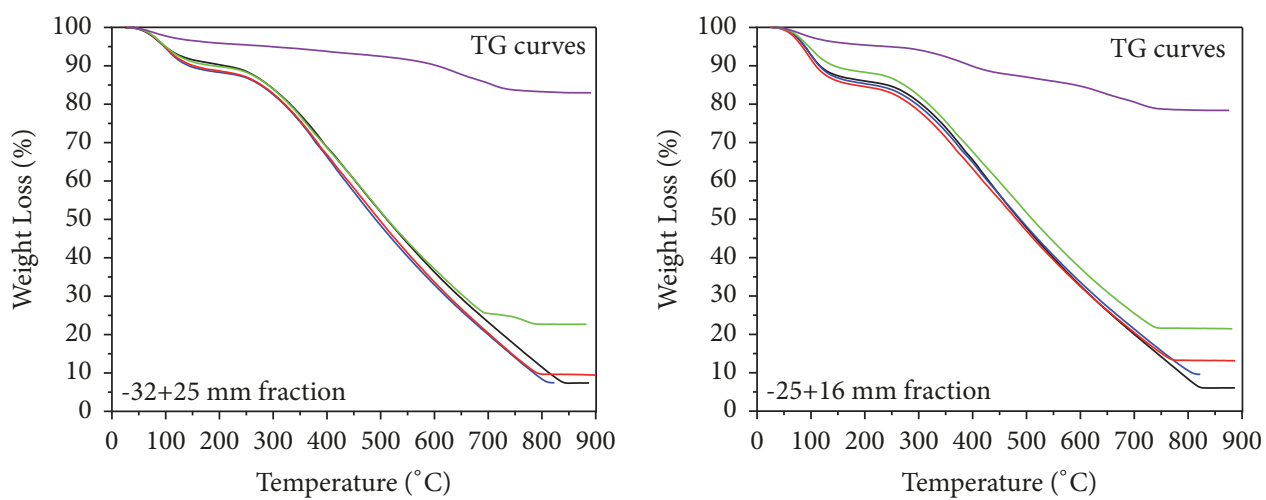

sample

$-1.2$

$-1.5$

sample

$-1.2$

1.5

$-1.3$

1.6

$-1.4$

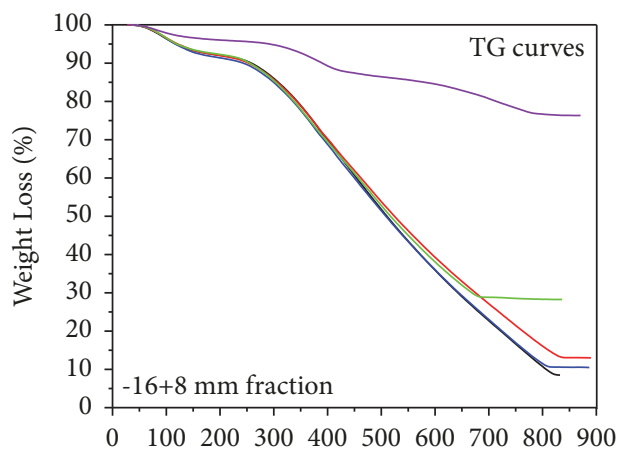

$-1.3$

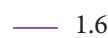

1.4

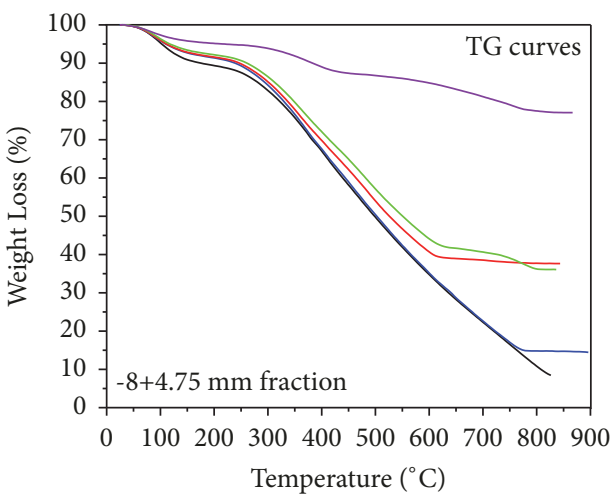

sample

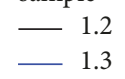

Temperature $\left({ }^{\circ} \mathrm{C}\right)$

Temperature $\left({ }^{\circ} \mathrm{C}\right)$

sample

$-1.2$

1.5
1.6

$-1.4$

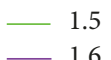

$-1.4$

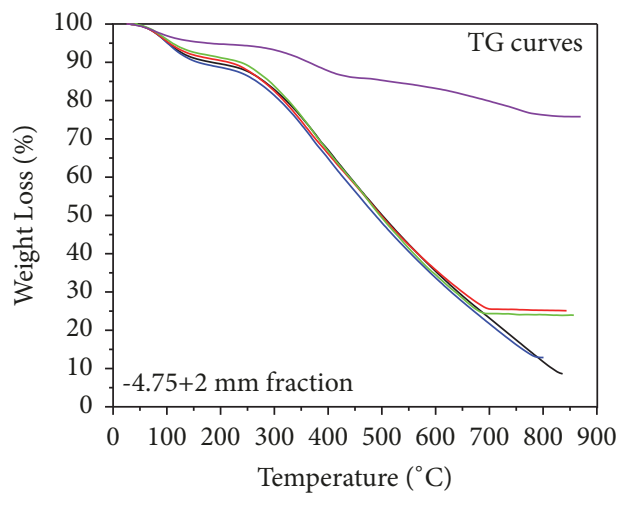

sample

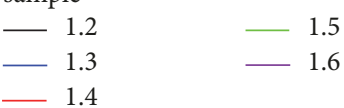

FIGURE 4: TG curves of floated materials for all fractions at different specific gravities of medium.

less inorganic materials in their structure started to ignition earlier as expected. The weight losses indicating these regions of TG curves could be easily seen from Figure 4 .

The DTG profiles of floated materials at different specific gravity mediums were shown in Figure 5. DTG results showed that the chemical reactivity of the coal samples was initially around $100^{\circ} \mathrm{C}$, due to the loss of water (first region) as all the samples were dried after the float and sink tests. Two devolatilization reaction regions were observed in Figure 5 (region second and third). The second region 

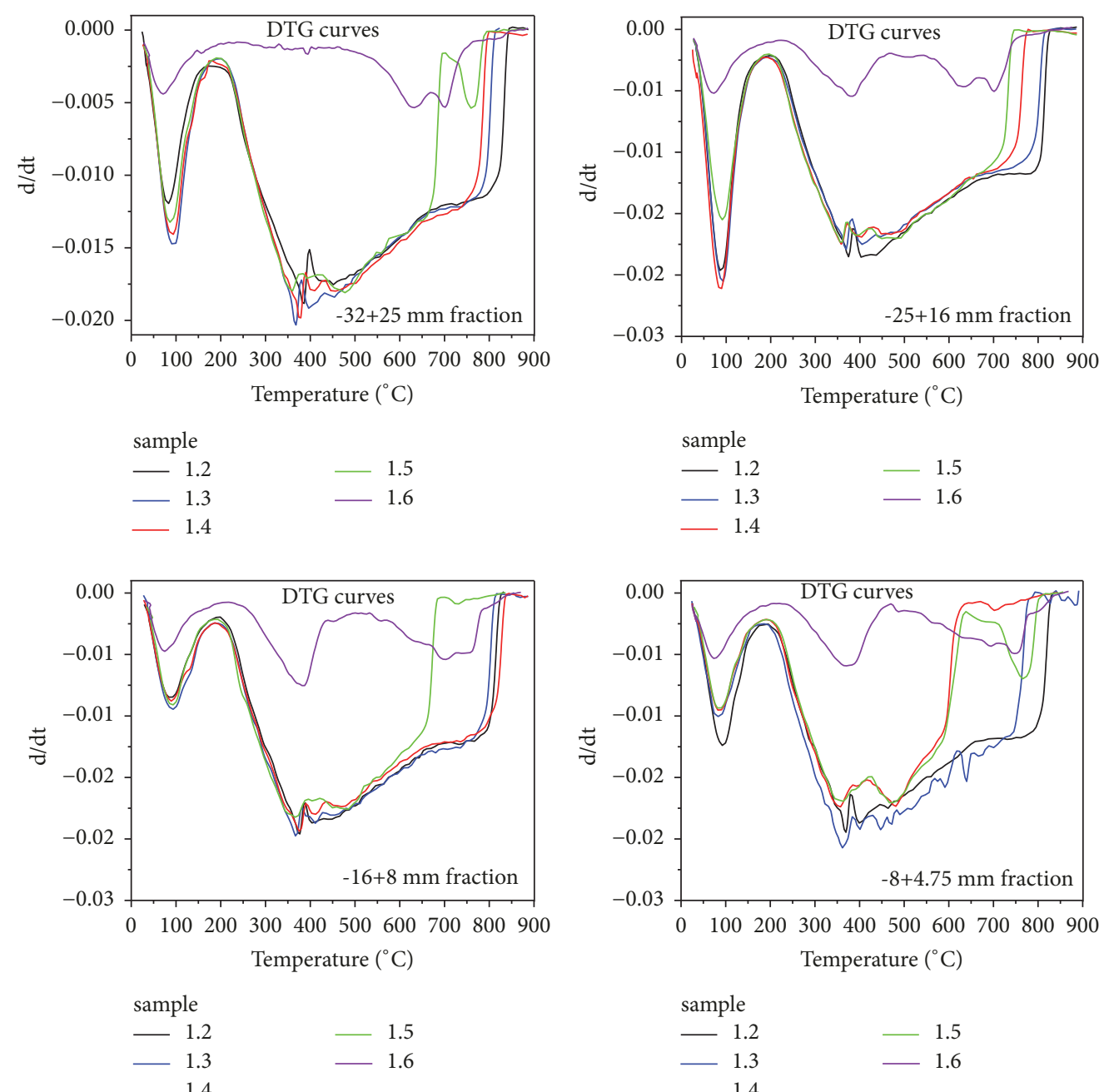

sample
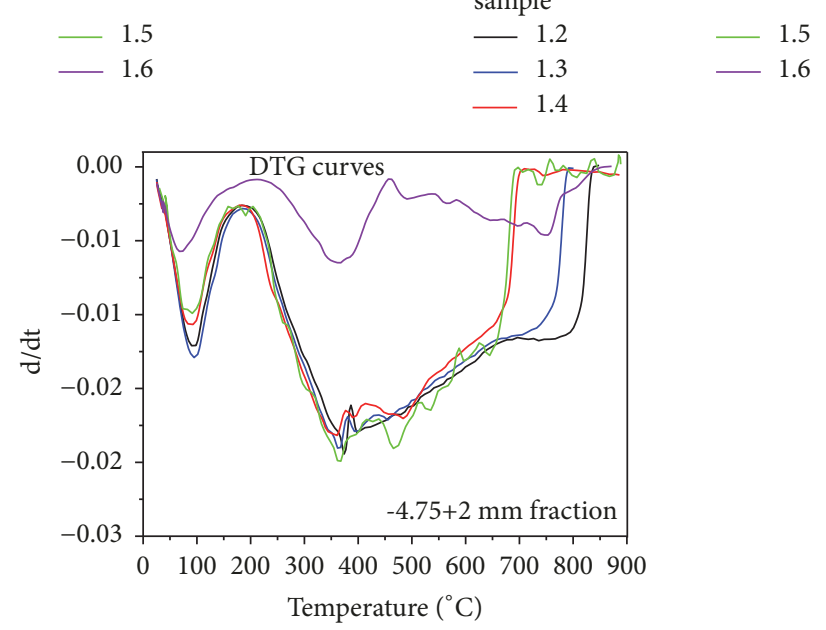

sample

$-1.2$

$-1.5$

$-1.4$

FIGURE 5: DTG curves of floated materials for all fractions at different specific gravities of medium.

approximately was started at $150^{\circ} \mathrm{C}$ and ended at $650^{\circ} \mathrm{C}$. The third region was also started at about $650^{\circ} \mathrm{C}$ and ended at $850^{\circ} \mathrm{C}$. The mass losses of coal samples were determined for enriched coals at different specific gravity of mediums and given in Table 3. The highest mass loss was determined in the second reaction region for all coal samples due to the combustion of carbonaceous part of sample. When the carbonaceous content was increased due to the enrichment of coal, the observed mass loss was also raised. 


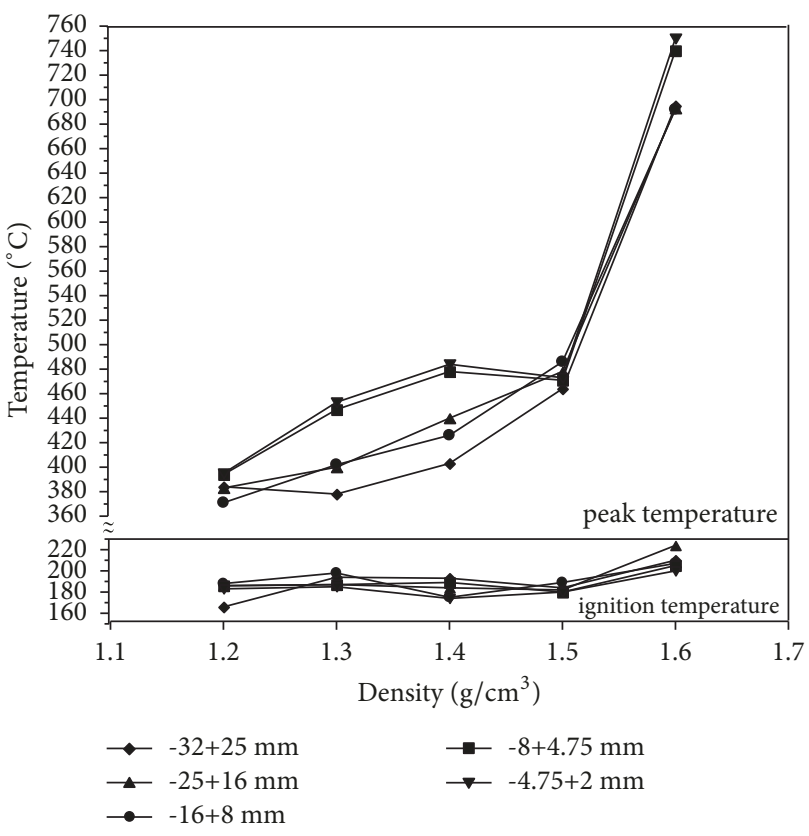

FIGURE 6: The ignition and peak temperatures of floated materials for all fractions at different specific gravities of medium.

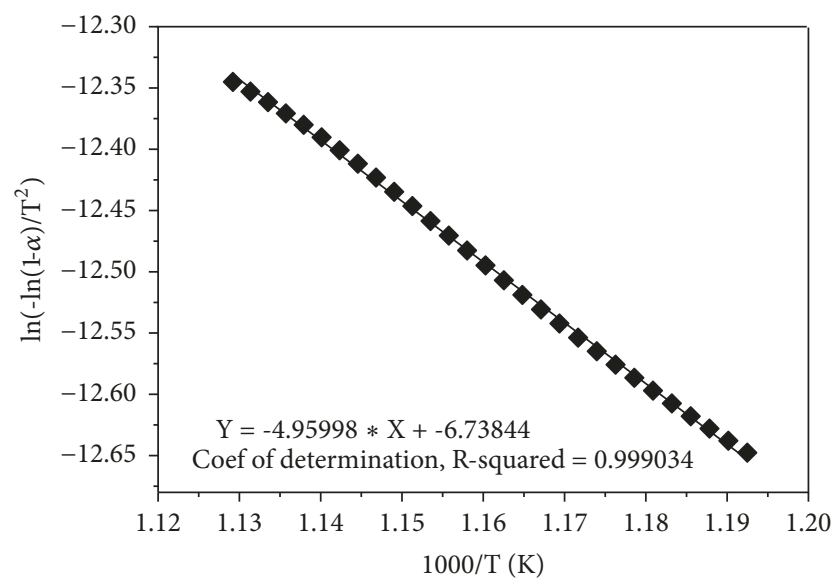

FIgURE 7: Plots of $\ln \left(-\ln (1-\alpha) / T^{2}\right)$ versus $1000 / T$ of the coal sample.

The ignition and peak temperatures are important temperatures for burning behaviour of coal. The ignition temperature represents the place where the combustion is started. The peak temperature is also known as the temperature at which the rate of weight loss is at maximum degree through the maximum combustion rate. The ignition and the peak temperatures were also obtained from thermographs of DTG and given in Figure 6. The peak temperature is the indicative of the combustibility of coal. The coal with a difficult combustible behaviour has the higher peak temperature. As seen from Figure 6, when the specific gravity of the medium was increased, the acquired peak temperatures were also increased and the maximum peak temperature was obtained at $1.6 \mathrm{~g} / \mathrm{cm}^{3}$ density of medium for all fractions. The ignition temperatures of coal also showed similar trend. Generally,
TABLE 3: The range of mass losses of coal samples at three reaction regions.

\begin{tabular}{lccc}
\hline Sample & \multicolumn{3}{c}{ Mass loss (\%) } \\
\hline 1.2 & I & II & III \\
1.3 & $8-13$ & $85-89$ & $2-3$ \\
1.4 & $8-14$ & $77-84$ & $1-2$ \\
1.5 & $7-14$ & $52-81$ & $1-3$ \\
1.6 & $7-10$ & $49-72$ & $2-5$ \\
\hline
\end{tabular}

coking coals pass through a plastic or softening state in the temperature range $350-450^{\circ} \mathrm{C}$ depending on their rank $[42,43]$ in the second region. In Figure 6, the obtained peak temperatures that ranged from $370^{\circ} \mathrm{C}$ to $480^{\circ} \mathrm{C}$ excepting the peak temperatures of coal which obtained $1.6 \mathrm{~g} / \mathrm{cm}^{3}$ density were in harmony with the literature. In the third region, the decomposition of the mineral matter occurred in the samples due to the decomposition temperatures of minerals in coal such as calcite, kaolinite in the range of $650-850^{\circ} \mathrm{C}$ [44]. Further bond breaking occurs and evolution of organic matter as tar, gases, and condensation reaction also takes place at this region. In addition, it was shown as in Figure 6 that a reduction was observed in ignition temperatures as the particle size decreased [15].

If Figures 3 and 6 were compared with each other, the strong correlation could be seen between the curves. The peak temperatures were already related to the combustibility of coal and consequently ash content. As a result, the higher ash content caused the superior peak temperature while lower temperature indicated more easily burnt samples.

3.3. Kinetic Analysis Results of the Coal Combustion. The activation energy of raw lignite sample was calculated as 41.24 $\mathrm{kJ} / \mathrm{mol}$ from the plots of $\ln \left(-\ln (1-\alpha) / T^{2}\right)$ versus $1000 / T$ and given in Figure 7.

The activation energies of floated material from the float and sink tests at $1.20,1.30,1.40,1.50$, and $1.60 \mathrm{~g} / \mathrm{cm}^{3}$ of densities mediums for $-32+25 \mathrm{~mm},-25+16 \mathrm{~mm},-16+8 \mathrm{~mm}$, $8+4.75 \mathrm{~mm}$, and $-4.75+2 \mathrm{~mm}$ sizes were also determined and the obtained results were given in Figure 8. The correlation coefficients of all samples were above 0.995 . These top level correlation coefficients indicate that corresponding independent first-order reaction model fits with experimental data very well. It is clear from Figure 8 that the activation energies of all fractioned samples which floated at $1.60 \mathrm{~g} / \mathrm{cm}^{3}$ density were the maximum. The quantity of inorganic mineral matter causing the ash content of coal structure was also measured about $80 \%$ at this density medium. The activation energies of coal are much related to the ash content itself [41]. When considering the specified ash content of samples at Figure 3, the combustible behaviour of samples such as peak temperatures from Figure 6 and the activation energies from Figure 8 showed similar tendency. The activation energy and ash content of raw coal were determined as $41.24 \mathrm{~kJ} / \mathrm{mol}$ and $35.84 \%$, respectively. When the ash content of coal was decreased to $7.34 \%$, the activation energy was $16.205 \mathrm{~kJ} / \mathrm{mol}$ 


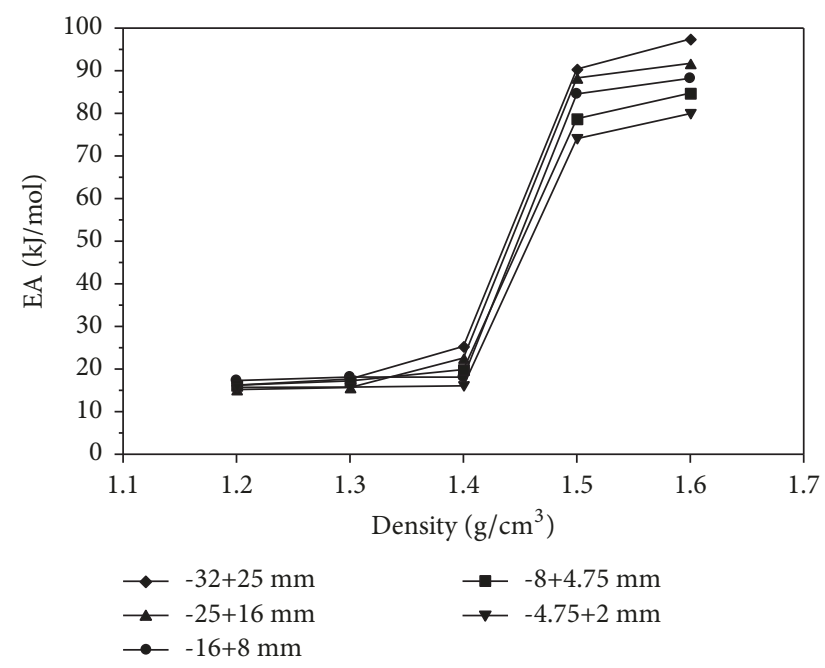

FIGURE 8: Activation energies of floated coal samples at different densities after the float and sink experiments.

which was the lowest value obtained (sample was 1.2 at $+32-25$ $\mathrm{mm}$ fraction). In a similar manner, when the ash content of coal sample was increased to the highest value of $83.03 \%$, the determined activation energy was $97.45 \mathrm{~kJ} / \mathrm{mol}$ (sample was 1.6 at $-32+25 \mathrm{~mm}$ fraction). Ozbas et al. [26] reached parallel results in their work. They investigated the kinetic analysis of three different coals and effect of enrichment on the kinetic parameters of coals. The obtained activation energies of cleaned samples were lower than the raw coal. Hicyilmaz et al. [24] reached comparable combustion behaviour for Tuncbilek coal in Turkey. They concluded that the activation energies of utilized coal decreased and reactivity of coal increased. Reaction with high activation energy needed a high temperature or a long reaction time as indicated in the literature [45]. The higher activation energies also imply that the reactions were more temperature-dependent [15]. Kok [23] obtained the activation energies of two different coals by TG-DTG methods in the range of $27.6-42.2 \mathrm{~kJ} / \mathrm{mol}$.

\section{Conclusions}

The purpose of this study is to relate the combustion reactivity of lignite with its physical properties. For the enrichment of the coal samples, the float and sink tests were performed and then the combustion behaviour of these coal samples was investigated. The thermal analysis methods and the kinetic analysis of thermogravimetric (TG) data were carried out by using the Coats Redfern kinetic model at nonisothermal conditions. The following conclusions were derived:

(1) The ash content of the coal obtained from the float and sink method had variations. The floated coal having minimum ash content (4.51\%) was attained from $-25+16 \mathrm{~mm}$ fraction at $1.20 \mathrm{~g} / \mathrm{cm}^{3}$ specific density medium. When the specific gravity of dense medium was arranged around the coal density (1.50 $\left.\mathrm{g} / \mathrm{cm}^{3}\right)$, the amount of floated material was decreased significantly.
(2) The observed weight losses of the samples from $1.6 \mathrm{~g} / \mathrm{cm}^{3}$ density for all fractions were lower than the others due to the higher quantity of inorganic materials as seen from the TG results. The main mass loss was due to the release of carbon dioxide and hydrogen in primary carbonization stage.

(3) The three regions were watched on thermographs. The first region was where the moisture left the coal and the second and third regions illustrated the devolatilization regions.

(4) Strong correlation was determined between the ash content and thermal behaviour of coal.

(5) The higher ash content of the sample caused the superior peak temperature and the lower temperature demonstrates the more easily burnt samples.

(6) The activation energies of coal are much related to the ash content itself according to the experimental results. The determined activation energies varied between $15.17 \mathrm{~kJ} / \mathrm{mol}$ and $97.45 \mathrm{~kJ} / \mathrm{mol}$. The enrichment of coal decreased the activation energy and increased the coal reactivity.

\section{Nomenclature}

E: Activation energy $(\mathrm{kJ} / \mathrm{mol})$

$R: \quad$ Gas constant $(\mathrm{J} / \mathrm{mol}, \mathrm{K})$

$T: \quad$ Absolute temperature $\left(\mathrm{K}_{\text {or }}{ }^{\circ} \mathrm{C}\right)$

$\alpha$ : Weight loss degrees

$t: \quad$ Time (min)

$W_{t}$ : Weight of coal at $\mathrm{t}$ time (g)

$W_{0}$ : Initial weight of coal $(\mathrm{g})$

$W_{f}$ : Final weight of coal burnt down (g)

$\beta$ : Rate of heating $(\mathrm{K} / \mathrm{min})$

$A_{r}$ : Arrhenius constant, (1/min).

\section{Data Availability}

The data used to support the findings of this study are available from the corresponding author upon request.

\section{Conflicts of Interest}

The authors declare that there are no conflicts of interest regarding the publication of this paper.

\section{Acknowledgments}

The authors greatly acknowledge the financial support provided by Scientific Research Project Fund of Selcuk and Dumlupinar Universities.

\section{References}

[1] GDMRE, General Directorate of Mineral Research and Exploration of Turkey. Annual Report, 2015. 
[2] Q. Zhang, Y. Tian, Y. Qiu, J. Cao, and T. Xiao, "Study on the washability of the Kaitai coal," Fuel Processing Technology, vol. 92, 2011.

[3] Y. Cebeci, U. Ulusoy, and I. Sonmez, "Determination of optimum washing conditions for a lignite coal based on ash and sulfur content," Fuel, vol. 123, 2014.

[4] Z. Aktas, F. Karacan, and A. Olcay, "Centrifugal float-sink separation of fine Turkish coals in dense media," Fuel Processing Technology, vol. 55, article 235, 1998.

[5] C. Tian, J. Zhang, Y. Zhao, and R. Gupta, “. Understanding of mineralogy and residence of traceelements in coals via a novel method combining low temperature ashing and float-sink technique," International Journal of Coal Geology, vol. 131, article $162,2014$.

[6] G. Wang, Y. Kuang, Z. Wang, L. Ji, and Y. Wang, "Rapid prediction of floating and sinking components of raw coal," International Journal of Mining Science and Technology, vol. 22, no. 5, pp. 735-738, 2012.

[7] J. Abbott and N. J. Miles, "Smoothing and interpolation of float/sink data for coals," Minerals Engineering, vol. 4, no. 3/4, 1991.

[8] B. Govindarajan and T. C. Rao, "Calendar of international conferences, symposia, courses and meetings of interest," Minerals Engineering, vol. 7, no. 11, article 1441, 1994.

[9] Y. Cebeci and N. Aslan, "Using float-sink data in simple equations to predict sulfur contents," Fuel Processing Technology, vol. 76, no. 3, pp. 231-239, 2002.

[10] C. E. Ozer, "A new simple method for density fractionation of finely sized coal," Minerals Engineering, vol. 86, article 114, 2016.

[11] S. Y. Yorulmaz and A. T. Atimtay, "Investigation of combustion kinetics of treated and untreated waste wood samples with thermogravimetric analysis," Fuel Processing Technology, vol. 90, no. 7-8, pp. 939-946, 2009.

[12] S. G. Sahu, P. Sarkar, N. Chakraborty, and A. K. Adak, "Thermogravimetric assessment of combustion characteristics of blends of a coal with different biomass chars," Fuel Processing Technology, vol. 91, article 369, 2010.

[13] X. Liu, M. Chen, and Y. Wei, "Combustion behavior of corncob/bituminous coal and hardwood/bituminous coal," Renewable Energy, vol. 81, 2015.

[14] S. Bada, R. Falcon, and L. Falcon, "Characterization and cofiring potential of a high ash coal with Bambusa balcooa," Fuel, vol. 151, pp. 130-138, 2015.

[15] K. Jayaraman, M. V. Kok, and I. Gokalp, "Thermogravimetric and mass spectrometric (TG-MS) analysis and kinetics of coalbiomass blends," Renewable Energy, vol. 101, article 293, 2017.

[16] J. Podder, T. Hossain, and K. M. Mannan, "An investigation into the thermal behaviour of Bangladeshi coals," Thermochimica Acta, vol. 255, no. C, pp. 221-226, 1995.

[17] M. Varol, A. T. Atimtay, B. Bay, and H. Olgun, "Investigation of co-combustion characteristics of low quality lignite coals and biomass with thermogravimetric analysis," Thermochimica Acta, vol. 510, no. 1-2, pp. 195-201, 2010.

[18] H. Haykiri-Açma, A. Ersoy-Meriçboyu, and S. Küçükbayrak, "Combustion reactivity of different rank coals," Energy Conversion and Management, vol. 43, no. 4, pp. 459-465, 2002.

[19] M. V. Kok, "Recent developments in the application of thermal analysis techniques in fossil fuels," Journal of Thermal Analysis and Calorimetry, vol. 64, article 1319, 2001.

[20] O. Oren and C. Sensogut, "Determination of Safe Storage Types for Coals with Regard to Their Susceptibility to Spontaneous
Combustion - Tuncbilek Coal Case," International Journal of Coal Preparation and Utilization, 2016.

[21] L. Ge, Y. Zhang, C. Xu, Z. Wang, J. Zhou, and K. Cen, "Influence of the hydrothermal dewatering on the combustion characteristics of Chinese low-rank coals," Applied Thermal Engineering, vol. 90, article 174, 2015.

[22] X. Wang, E. Cotter, K. N. Iyer, J. Fang, B. J. Williams, and P. Biswas, "Relationship between pyrolysis products and organic aerosols formed during coal combustion," Proceedings of the Combustion Institute, vol. 35, article 2347, 2015.

[23] M. V. Kok, "Simultaneous thermogravimetry-calorimetry study on the combustion of coal samples: effect of heating rate," Energy Conversion and Management, vol. 53, article 40, 2012.

[24] C. Hicyilmaz, K. E. Ozbas, and M. V. Kok, “The benefit of coal washing from the view of combustion kinetics," in Proceedings of the 13th Turkish Coal Congress, Zonguldak/Turkey, 2002.

[25] T. Das, B. K. Saikia, D. K. Dutta, D. Bordoloi, and B. P. Baruah, "Agglomeration of low rank Indian coal fines with an organic binder and the thermal behavior of the agglomerate produced: Part I," Fuel, vol. 147, article 269, 2015.

[26] K. Ozbas, M. V. Kok, and C. Hicyilmaz, "Comparative kinetic analysis of raw and cleaned coals," Journal of Thermal Analysis and Calorimetry, vol. 69, article 541, 2002.

[27] D. C. Cronauer, J. T. Joseph, A. Davis, J. C. Quick, and P. T. Luckie, "The beneficiation of Martin Lake Texas lignite," Fuel, vol. 71, no. 1, pp. 65-73, 1992.

[28] J. W. Cumming and J. McLaughlin, "The Thermogravimetric Behaviour of Coal," Thermochimica Acta, vol. 57, article 253, 1982.

[29] C. Sensogut, H. Ozsen, and A. Demirbas, "Combustion characteristics of 24 lignite samples," Energy Sources, Part A: Recovery, Utilization, and Environmental Effects, vol. 30, no. 5, pp. 420428, 2008.

[30] T. J. Kang, H. Namkung, D. H. Jang, and H. T. Kim, "Experimental study on different heating rate kinetics of Indonesian and Inner Mongolian low rank coal for catalytic gasification," Journal of Industrial and Engineering Chemistry, vol. 20, article 2095, 2014.

[31] GDMRE, General Directorate of Mineral Research and Exploration of Turkey. The lignite inventory of Turkey, 2010.

[32] S. Duzyol and C. Sensogut, "The relation between hydrophobic flocculation and combustion characteristics of coal," Fuel Processing Technology, vol. 137, pp. 333-338, 2015.

[33] J. W. Cumming, "Reactivity assessment of coals via a weighted mean activation energy," Fuel, vol. 63, article 1436, 1984.

[34] W. A. Kneller, "Physicochemical characterization of coal and coal reactivity: a review," Thermochimica Acta, vol. 108, article 357,1986

[35] N. B. Sarkar, P. Sarkar, and A. Choudhury, "Effect of hydrothermal treatment of coal on the oxidation susceptibility and electrical resistivity of HTT coke," Fuel Processing Technology, vol. 86, no. 5, article 86, 2005.

[36] A. W. Coats and J. P. Redfern, "Kinetic parameters from thermogravimetric data," Nature, vol. 201, no. 4914, pp. 68-69, 1964.

[37] B. Wills, "An Introduction to the Practical Aspects of Ore Treatment and Mineral Recovery," in Mineral Processing Technology, Pergamon Press, Oxford, UK, 8th edition, 2015.

[38] J. B. Howard, "Fundamentals of coal pyrolysis and hydropyrolysis," in Chemistry of coal utilization, M. A. Elliott, Ed., WileyInterscience, Toronto, Canada, 1981. 
[39] P. R. Solomon, M. A. Serio, and E. M. Suuberg, "Coal pyrolysis: Experiments, kinetic rates and mechanisms," Progress in Energy and Combustion Science, vol. 18, no. 2, pp. 133-220, 1992.

[40] P. R. Solomon, M. A. Serio, R. M. Carangelo et al., "Analysis of the Argonne Premium Coal Samples by Thermogravimetric Fourier Transform Infrared Spectroscopy," ENERGY \& FUELS, vol. 4, no. 3, pp. 319-333, 1990.

[41] K. E. Ozbas, S. Bilgen, C. Hicyilmaz, and M. V. Kok, “Thermogravimetric behaviour of some Turkish Iignites of different sizes," Fizykochemiczne Problemy Mineralurgii, vol. 32, article 149, 1998.

[42] H. D. Glass, "Differential thermal analysis of coking coals," Fuel, vol. 34, article 253, 1955.

[43] C. Moon, Y. Sung, S. Ahn, T. Kim, G. Choi, and D. Kim, "Thermochemical and combustion behaviors of coals of different ranks and their blends for pulverized-coal combustion," Applied Thermal Engineering, vol. 54, no. 1, pp. 111-119, 2013.

[44] J. V. O'Gorman and P. L. Walker, "Thermal behaviour of mineral fractions separated from selected American coals," Fuel, vol. 52, article 71, 1973.

[45] M. J. Lazaro, R. Moliner, and I. Suelves, "Non-isothermal versus isothermal technique to evaluate kinetic parameters of coal pyrolysis," Journal of Analytical and Applied Pyrolysis, vol. 47, pp. 111-125, 1998. 


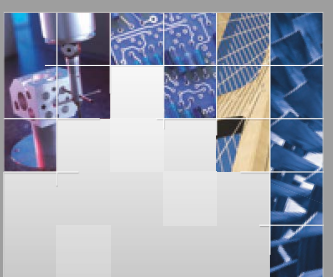

\section{Enfincering}
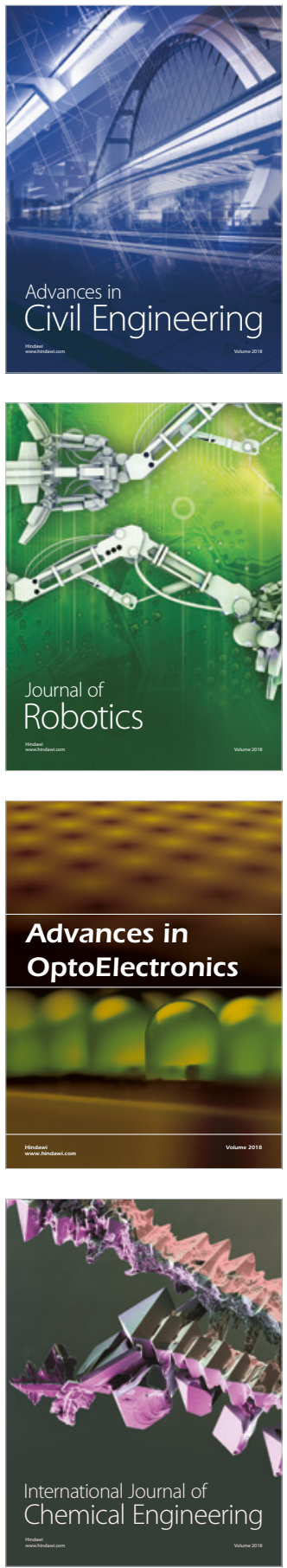

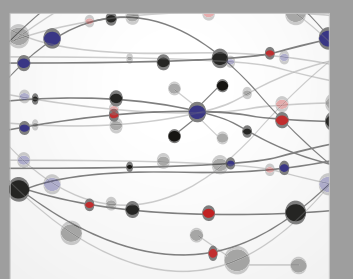

\section{Rotating \\ Machinery}

The Scientific World Journal

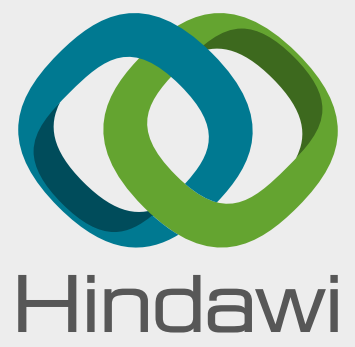

Submit your manuscripts at

www.hindawi.com
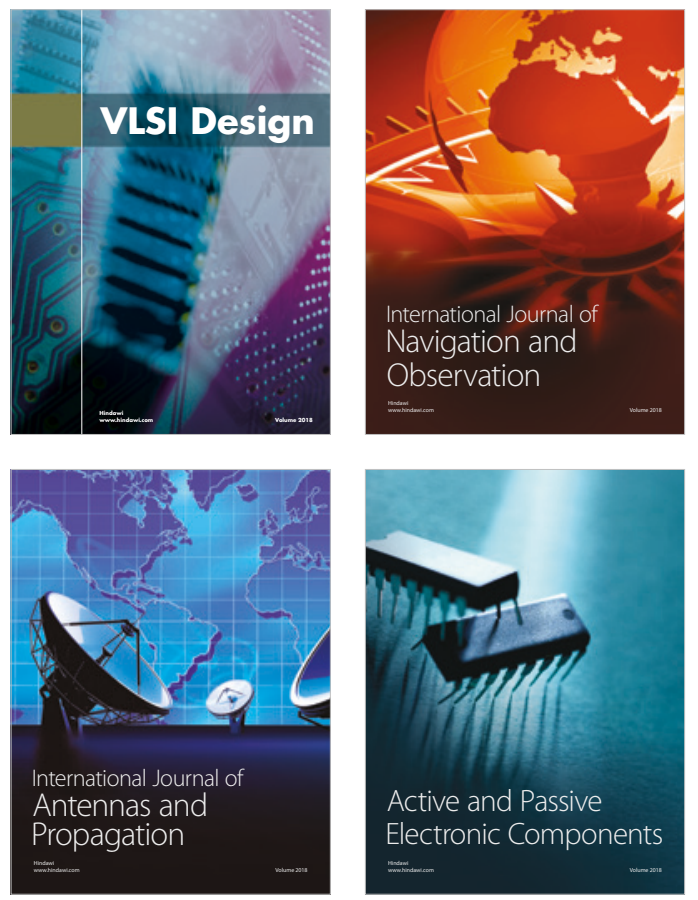
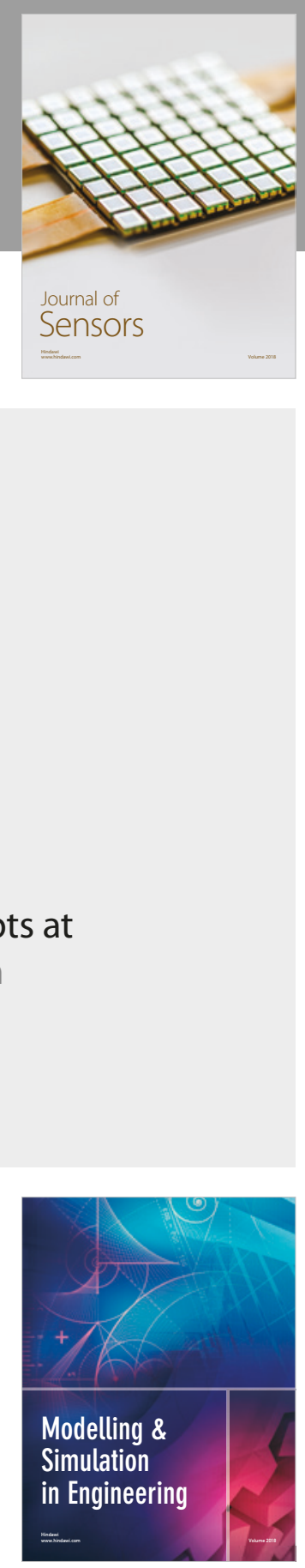

\section{Advances \\ Multimedia}
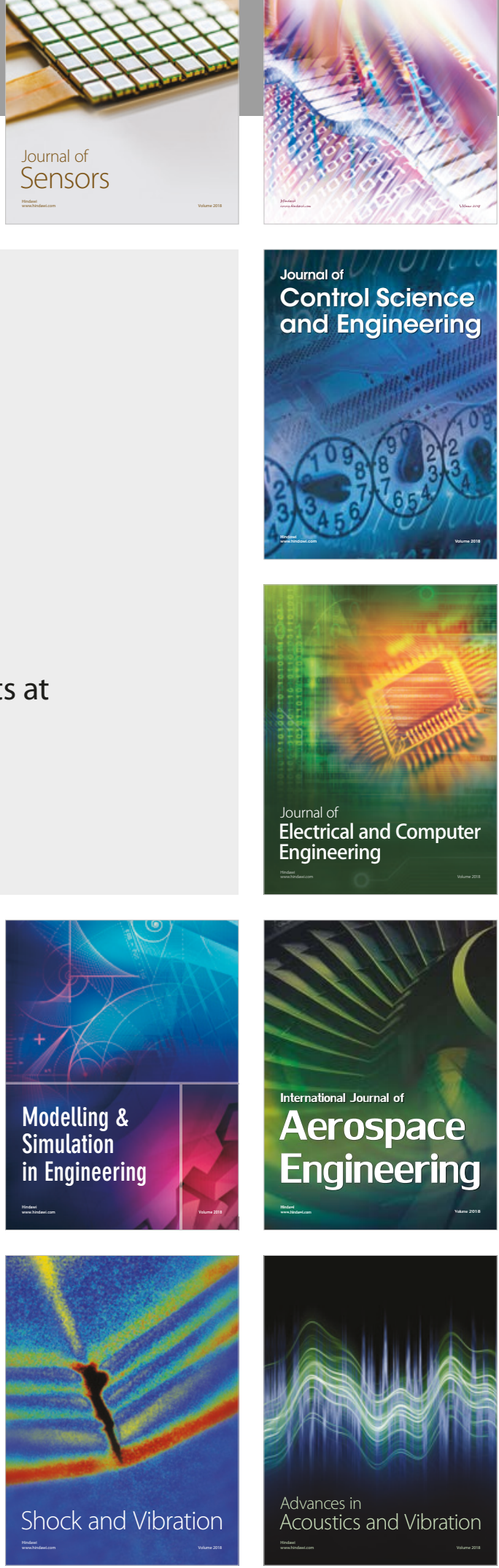